\title{
Unmasking the Therapeutic Potential of Biomarkers in Type-1 Diabetes Mellitus
}

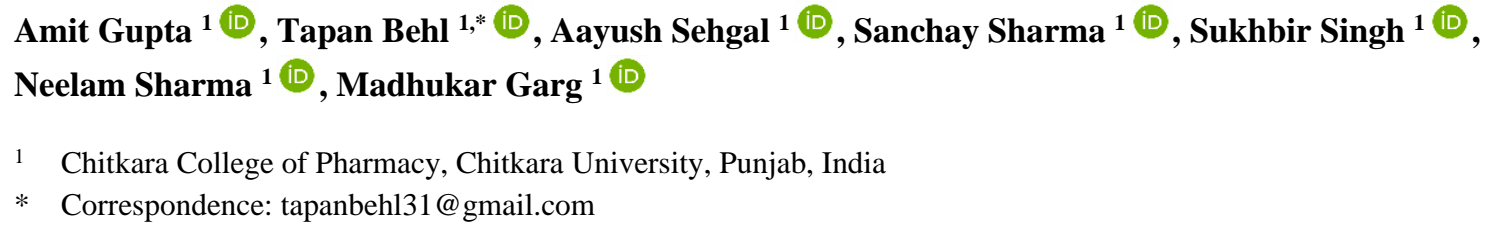

Received: 4.01.2021; Revised: 1.02.2021; Accepted: 3.02.2021; Published: 7.02.2021

\begin{abstract}
Diabetes mellitus is one of the most widely spread disorders affecting millions of people every year. Uncontrolled or chronic diabetes may lead to diabetes-associated complications. Conventional therapies often fail to define clear parameters and do not provide early detection of diabetes and pre-diabetes. Thus, there is a need to find a diagnostic method that can non-invasively help detect and prevent diabetes and associated complications. To combat this challenge, biomarkers' use has gained importance in the early detection of pre-diabetes and diabetes-associated complications. Detailed analyses from research and review articles were performed to elucidate the true potential of biomarkers in early detection, disease pathogenesis, risk prediction, and therapeutic monitoring in diabetes and associated complications. This review discusses the type of biomarkers, the progress, challenges, and short-coming related to biomarkers implications. This review also discusses the future directions in developing type-1 diabetes biomarkers focusing on genetic, transcriptomic, and proteomic aspects. From the findings from the available data on research and development carried out in biomarker research, significant improvements and conclusive studies have been conducted to confirm the beneficial clinical effect in early detection of diabetes using the biomarkers. The data from these studies promise novel biomarkers' implication in detecting pre-diabetes, which may help reduce the mortality and morbidity associated with diabetes and associated complications.
\end{abstract}

Keywords: biomarkers; type-1 diabetes; prediction; pathogenesis; pre-diabetes; diabetes-associated complications.

(9) 2021 by the authors. This article is an open-access article distributed under the terms and conditions of the Creative Commons Attribution (CC BY) license (https://creativecommons.org/licenses/by/4.0/).

\section{Introduction}

Diabetes mellitus is considered one of the most widely spread "lifestyle" worldwide. It is a chronic metabolic disorder of the endocrine system affecting millions of people every year. In this condition, the endocrine system's homeostasis is disrupted due to the pancreas' inability to produce sufficient insulin. Thus, the body cannot effectively utilize the insulin that is produced in the human body. Uncontrolled diabetes can lead to metabolic disorders, leading to acute and chronic complications that may require immediate medical interventions. Some authors had also described diabetes mellitus as a syndrome of multiple etiologies characterized by disturbance in the human system of carbohydrates, lipids, and protein metabolism. This imbalance leads to a defect in insulin secretion, action exerted by insulin, or the combination of both these responses. As a result, chronic diabetes is associated with disrupting the organ function involving the eyes, kidneys, cardiac system, and blood vessels. These complications can lead to morbidity and mortality in diabetic patients. As per the analysis by ICMR (Indian 
Council of Medical Research) and WHO (World Health Organization) [1], the prevalence of diabetes is more in developing countries like India as compared to other developed countries. As per epidemiology, the prevalence of diabetes is projected to around 134.3 million by the year 2045.

Type-1 diabetes (T1D), also known as autoimmune diabetes, is a chronic metabolic disorder that affects the pancreatic $\beta$-cells and targets the human body's endocrine system [2]. This disorder is primarily seen during childhood or adolescence, where insulin deficiency is characterized by pancreatic $\beta$-cell loss [3]. In this autoimmune condition, the body's immune system attacks $\beta$-cell of the pancreas by producing specific antibodies against its own cells. The absence of $\beta$-cells results in hyperglycemia, which is generally managed by exogenously administering insulin injections. In most of the scenarios of T1D, it has been seen that 80 to $90 \%$ of the $\beta$-cells are deteriorated or damaged [1]. In this condition, it becomes very difficult to intrude the disease progression of T1D, which can lead to several micro and macro-vascular complications [2]. The numbers of cases of diabetes are alarmingly increasing, which accounts for an average annual increase of 2 to $5 \%$ worldwide [3]. The symptoms of T1D usually start appearing during childhood to adulthood, with the maximum incidence rate at the age of 12 to 14 years. T1D diabetes is also accompanied by micro and macro-vascular complications, which can be chronic or acute by nature [4-7]. As described by American Diabetes Association (ADA) 2016, the diagnostic criteria for determining diabetes mellitus are based on the signs and symptoms associated with abnormal glucose metabolism regardless of diabetes type and the age of onset. Most of the cases of T1D remain undiagnosed, which can cause serious implications. Thus, it becomes crucial to predict T1D by using diagnostic markers, often called 'biomarkers', which are using a platform of genetic markers, metabolic markers, and islet autoantibodies (AAb), in the diagnosis at early stages.

\section{Need of Biomarkers and their Importance}

A biomarker in medicine is a perceptible indicator and is defined as "any substance or process that is measurable in the body which is capable of influencing or helps in the prediction of diseased state" [8-9].

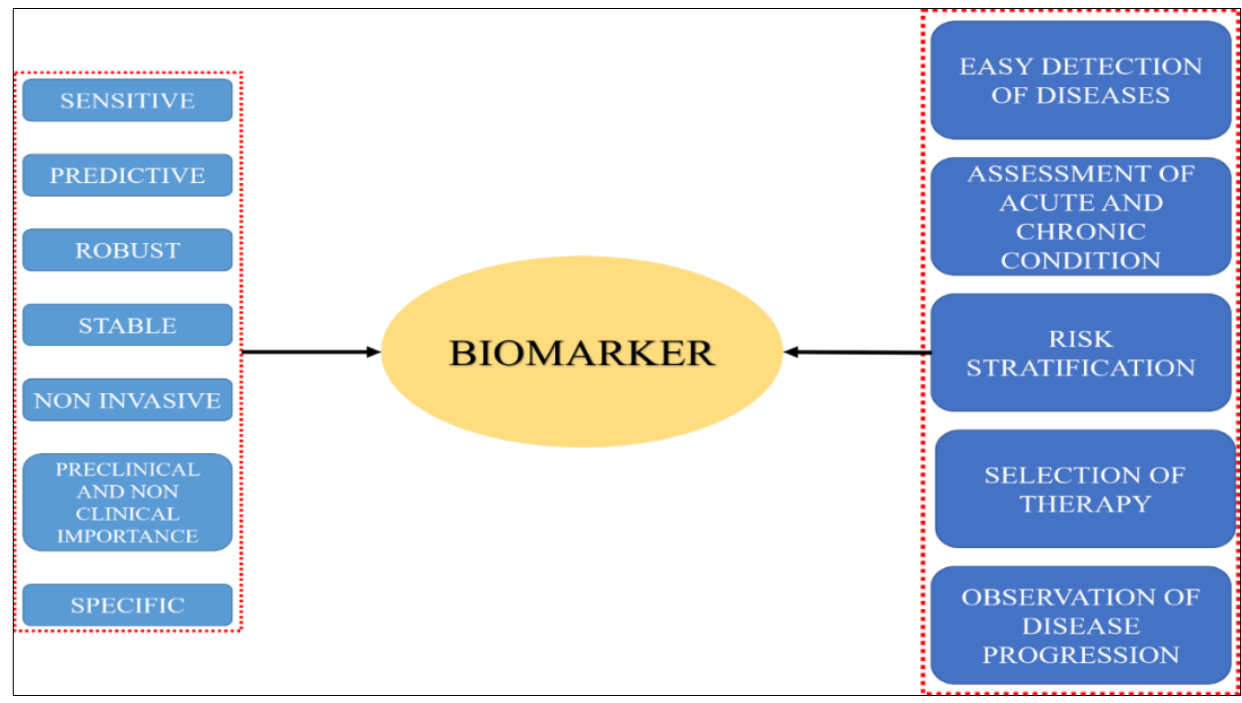

Figure 1. Applications and importance of biomarkers in therapeutic monitoring of various disorders.

These biomarkers can identify patients with the subclinical disease before the disease's clinical development or symptomatic development. Thus, the use of biomarker can prove an 
asset in early detection and may prove beneficial in treating or mitigating disease. These biomarkers hold tremendous potential in the ease of identifying and preventing the disease at the sub-clinical stage, which may have better therapeutic implications in managing various diseases.

Generally, biomarkers are present in the human body itself, and nowadays, they are synthesized in laboratory conditions using various chemical and biochemical methods. The therapeutic implications of biomarkers are being utilized by epidemiologists, physicians, and health care professionals. Due to various mechanisms involved in disease progression, the science behind biomarkers' development has to be well understood [10]. The main actions of biomarkers and their importance are depicted in Figure 1.

\section{Biomarkers for T1D}

Due to the development of various lifestyle disorders involving multiple cellular and metabolic pathways, early detection or prognosis of disease has become of utmost importance today. Biomarkers, known as indicators of normal to abnormal physiological and pathological functions, serve as a tool for prognosis, clinical diagnosis, and therapeutic monitoring of various diseases. For generations, the use of various biomarkers involving blood serum has unleashed the new era of explorations in biomarker research. However, these biomarkers' development is still not put into practice due to the limited availability of information regarding the risk involved, which might supersede its benefits. The most promising biomarkers utilized in the detection of pre-diabetes are 'Serum Biomarkers'. However, the therapeutic implications of the serum biomarkers for the prediction and management of T1D have to be well understood [11]. Although the etiology of T1D has already been established, only a few biomarkers such as glucose, HbA1c, C-peptide, miRNA, and some selective AAb are utilized for early detection of diabetes. Due to an array of pathways involved in the progression and pathogenesis of T1D, we still do not have appropriate biomarkers to reflect $\beta$-cell functioning or homeostasis of blood glucose levels in the body. This review paper discusses how biomarkers' utility may prove to be a foundation stone in the early detection and management of T1D. This review also highlights some of the novel biomarkers under pipeline research for the therapeutic management of T1D. It may prove beneficial in the mitigation of diabetes-associated complications [12].

Due to the high cost involved in the utilization of biomarkers, it is still not therapeutically used in the early detection of T1D. Various studies are being carried out to explore novel biomarkers that may prove to be cost-effective and can help in the early detection of T1D, which will ultimately prove beneficial in preventing diabetes-associated complications associated with diabetes, which includes diabetic neuropathy in diabetic neuropathy.

\section{Prediction of Biomarkers in T1D in Children}

T1D is one of the major concerns, especially in children. Since it is an autoimmune condition, prior diagnosis and timely treatment are of utmost importance. In T1D, the destruction of insulin-producing $\beta$-cells of the pancreas is mainly associated with acute and chronic complications in children, which require intervention on priority [13,14]. The current treatment in this group of patients is mainly exogenous insulin, which helps maintain blood glucose levels in the body. In developed and developing countries, it has become a matter of great concern in predicting and preventing T1D, ultimately preventing diabetes-associated 
complications. Also, due to the about $3 \%$ per year increase in T1D incidence rates, the emphasis has been put on developing novel methods that may prove beneficial in predicting and thereby acts as a preventive method in this disorder's pathogenesis [15]. Although sufficient data is available for the mechanism involved in the pathogeneses of T1D, however, factors responsible for developing this disorder, especially in children, are still to be well understood. This disease's progression involves a cascade of cellular, molecular and metabolic factors, which hinders early detection of this disease. Various traditional biomarkers have already been explored, which had shown effectiveness against pre-diabetes and diabetes. These traditional biomarkers include HbA1C, FA, GA, and OGTT. Various clinical and pre-clinical studies had been conducted over the past few decades to develop novel biomarkers for the early detection of T1D. However, we still lack data that can help us to establish the benefit-risk profile of these biomarkers in the early detection of diabetes [16]. The detailed description regarding the risk assessment of detection of T1D in children is depicted in Figure 2.

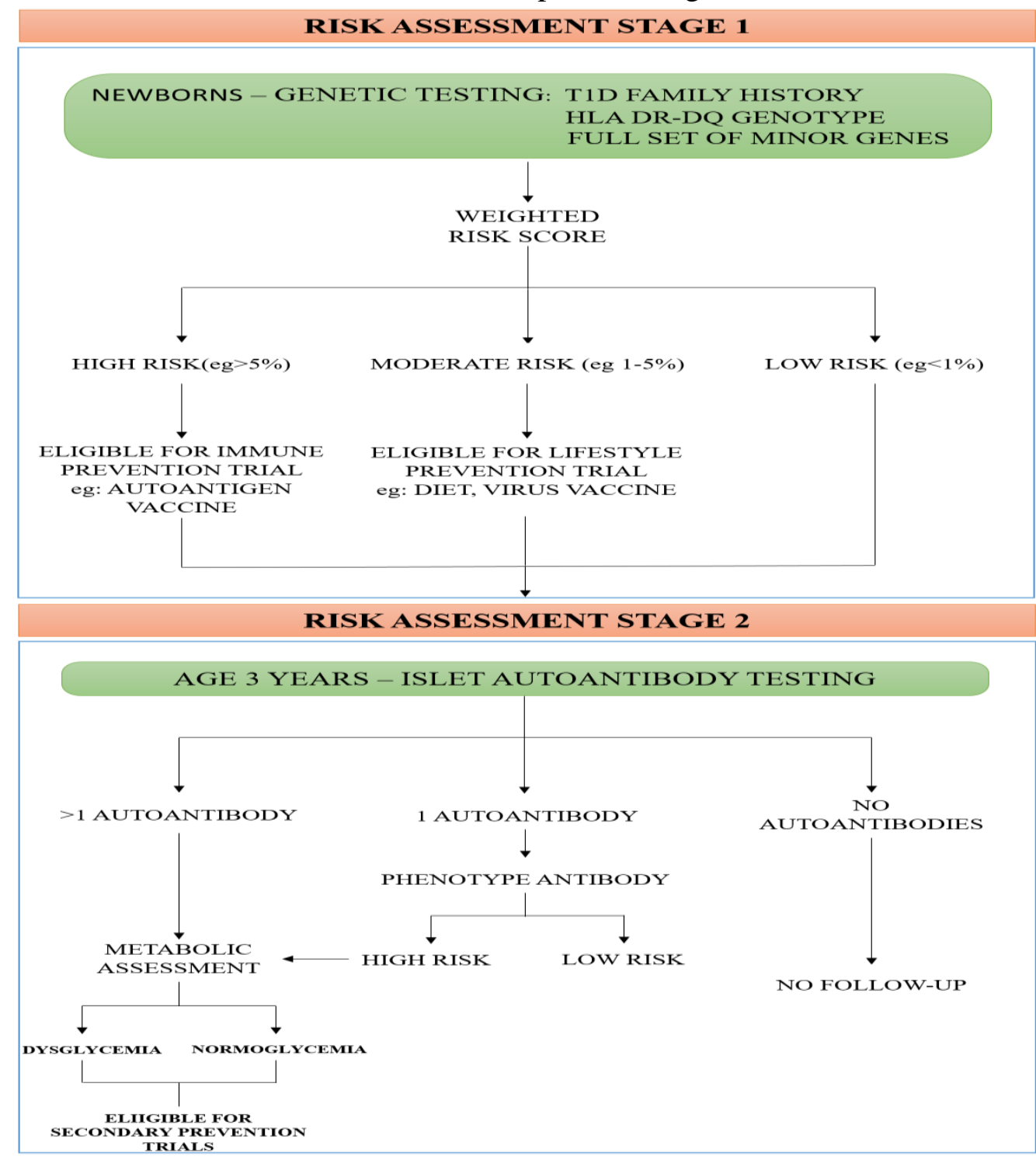

Figure 2. Risk assessment in newborns and children (greater than 3 years age group).

\subsection{Prediction of Type 1 diabetes using serum biomarkers.}

Various factors, including genetic and specific environments, are associated with modifying triggers for the development of T1D. However, still lucid criteria of diagnosis cannot be established using this approach. The current biomarkers used in the diagnosis of T1D 
depend significantly upon the hyperglycemic indices and their consequences, i.e., levels of high glucose in the blood or glycated hemoglobin, which in combination aid in the exclusive diagnosis of T1D and differentiate it from other subtypes of diabetes [17].

The diagnosis of T1D by serum biomarkers includes the combination of glucose and other glycated molecules, including C-peptides [18]. Due to the short-coming of late identification of diabetes, where almost more than $90 \%$ of $\beta$-cells of the pancreas producing insulin had been damaged, serious considerations for identifying and developing prognostic biomarkers for timely detecting T1D have to be focused on which can only provide a solution to this problem.

\subsubsection{Glucose-related biomarkers.}

An arbitrary measurement of plasma glucose $\geq 200 \mathrm{mg} / \mathrm{dL}$ can diagnose diabetes in patients with hyperglycemic symptoms or hyperglycemic crisis episodes. In the latter scenario, the blood-based testing of glucose includes hemoglobin (Hb1 Ac) and oral glucose tolerance test (OGTT). Both these tests for diagnosis are different, based on their sensitivity, methodology, and specificity. According to the ADA criterion for the diagnosis of diabetes, $\mathrm{HbA} 1 \mathrm{c}$ levels are mentioned to be less than $6.5 \%$. The fasting plasma glucose (FPG) should be less than or equal to $126 \mathrm{mg} / \mathrm{dL}$ should not be exceeding $200 \mathrm{mg} / \mathrm{dL}$ [19].

\subsubsection{Autoantibody-based biomarkers.}

Nearly $5-10 \%$ of all the subtypes of diabetes are classified as T1D. The existence of specific AAb embarks the differentiation of T1D from T2D and other subtypes. Five frequently examined types of AAb are used in the diagnosis of T1D [20-22]. In any case, one of the AAb is present in more than 95\% of the T1D affected individual [23]. Although the AAbs have been validated through highly confident assays, they fail to diagnose all types of T1D sufficiently. Due to the presence of various patients lacking the subsets of AAbs mentioned above, indicating the tests' insensitivity or potential of distinct auto-antigen-mediated destruction of $\beta$-cells in T1D patients, there is a need to combat this issue associated with antibody-based biomarkers.

\subsubsection{C-peptide.}

Insulin, which was formerly synthesized as pre-proinsulin, is converted to active proinsulin after dividing the peptide signals in the cell's endoplasmic reticulum. The synthesized pro-insulin gets stored in the little vesicles, which further cleaves to form the active insulin hormone and peptide- $\mathrm{C}$, both releasing in equimolar concentrations from the mature granules with the simultaneous release of the unchanged pro-insulin [24]. The half-life of insulin reported is just 3-5 minutes compared against the peptide-C and pro-insulin because of liver intake and utilization. The serum-C peptide level had been considered a coherent and sensitive marker for measuring the functioning of $\beta$-cells, which easily can differentiate between the autoimmune types of diabetes with other diabetes subtypes [25]. Combining C-peptides with other complication factors such as BMI can enhance disease progression interpretation [26]. Measurement of C-peptide is among the most preferred therapy outcomes for clinical studies. It aims to preserve or improve endogenous insulin secretion in T1D patients; however, it is still unreliable [27]. The measurement of hyperglycemia and blood glucose markers combined with $\mathrm{AAb}$ testing is the most reliable method to evaluate diabetes in the general population. The 
T1D can be manifested when only $10-20 \%$ of the $\beta$-cells that produce insulin are functioning during diagnosis [28].

\subsection{Prediction using transcriptomic biomarkers.}

The transcriptome is considered the next advanced level individual phenotype similar to the human genetic expression [29]. Genetic expression is a quantitative trade that is inherited but is also affected by environmental changes. A transcriptome is a set of RNA molecules used to reflect cellular machinery's life status [Error! Reference source not found.-Error! Reference source not found.]. It is considered that transcriptome can respond quickly to environmental factors, and this implication may be used in the early detection of disease. Various studies have confirmed that most genome generates a kind of RNA transcript [Error! Reference source not found.]. The implications of these transcripts have been studied in detail and are considered potential biomarkers in various pathological conditions, including cancer, an autoimmune condition, inflammatory disorders, and various cardiometabolic conditions [Error! Reference source not found.-Error! Reference source not found.]. Various advanced studies on genetic expression microarray have been conducted, which had shown more than 48,000 transcripts responsible for most of the protein-coding genes, which were later explained in the RefSeq and UniGene database [Error! Reference source not found.,Error! Reference source not found.]. These databases generate gene expression data from the available transcriptomic database and are further analyzed by RefSeq and UniGene. This helps in predicting biomarkers in the early detection of various diseases [41-Error! Reference source not found.].

MicroRNA (miRNA) are non-coding, small RNAs that help regulate gene expression by biding to mRNA sequence, reducing the translation, or even acting by inducing the degradation of bound mRNAs [Error! Reference source not found.-Error! Reference source not found.]. These miRNAs are responsible for recognizing various mRNAs; thus, a single miRNA may control various developmental or metabolic pathways [Error! Reference source not found.Error! Reference source not found.]. The implication of transcriptomic biomarkers in evaluating gestation diabetes mellitus has always raised a question mark to the scientific domain [Error! Reference source not found.-Error! Reference source not found.].

\subsection{Prediction using proteomic biomarkers.}

Proteomic studies are carried out to quantify biological samples, including urine, saliva, serum or plasma, and cerebrospinal fluids [53]. Proteomics may be considered a future therapeutic tool to evaluate patients who are more prone to experience side effects due to medication [Error! Reference source not found.-Error! Reference source not found.]. Each patient proteome can be used to determine the patient's phenotype, which may or may not respond to the therapeutic regimen [Error! Reference source not found.]. Thus, this approach may be used as a baseline risk prediction method to determine medication safety in patients [Error! Reference source not found.].

The protein levels comprise aberrant genetic and genomic transformations, which correlate with the cell functioning and affect health scenarios [Error! Reference source not found.]. Thus, proteins can be vigilantly employed as biomarkers for diabetes diagnosis, prediction, monitoring, and management [Error! Reference source not found.-Error! Reference source not found.]. The most commonly used proteomic biomarkers for the disease include islet AAbs present in serum. They can significantly predict disease development. A wide array of 
AAb has been discovered since the 1970s that are employed in T1D [Error! Reference source not found.-67]. The autoantibody assessment has changed drastically. ZnT8A successfully improvised the testing technique of disease and enhanced its value. AAbs are tedious to measure and are not precise and sensitive; thus are poor biomarkers [68,69]. The islet AAbs have no indulgence in disease pathology but are principal hallmarks recognizing the response to autoimmune auto-antigens and can be used in research clinical studies and T1D prevention.

\subsection{Prediction using serum biomarkers.}

Various factors such as environmental triggering, genetics, and other modifying factors lead to disease progression, but sadly none of them can serve lucid diagnosis criteria. The hyperglycemic index is the principal diagnostic biomarker still researchers rely upon. Proteins are the main executioners for all aberrant transformations in genetics and form the basis of biomarkers for identifying specific diseases. Analysis of expression of protein/peptide (proteomics), including post-translational modifications (PTMs) levels for T1D, potentiates noteworthy impacts in the prediction and prognosis of the disease [70]. It is challenging to analyze the serum proteins based on the vibrant range and complexity of serum proteins and low levels of the appropriate biomarkers that are disease and tissue cell-specific. The human and disease heterogeneity are highly variant, thus complicates the analysis of proteomics from the serum and makes it challenging to analyze significant change [71]. The enormously low pancreatic $\beta$-cell mass compared to total body mass besides the proliferating nature of loss of $\beta$-cells, the research on protein biomarkers present in serum specific to the disease is still in the budding stage [72].

\subsubsection{Post-translational modifications (PTMs).}

There is limited information available regarding the pathway associated with immune tolerance associated with diabetes from the available literature. The cross-talk role of immune cells and antigen $\beta$-cells is highly prominent in the disease etiology. The $\beta$-cell and endoplasmic reticulum oxidative stress is triggered by inflammation, which causes splicing and $\beta$-cell misfolding at post-translational levels, often called PTMs. They are highly different from their native proteins and lead to tolerance breakdown. From the available data, it can be concluded that in patients of T1D, some newly discovered 'antigens' can act as novel therapeutic agents. These agents may suppress the autoimmune condition in patients on regeneration therapy or islet cell replacement therapy. The auto-antibodies against neo-antigens act supplementary to existing AAb [73]. Thus, utilizing this mechanism may provide futuristic insights for the utilization of biomarkers in diabetes.

\subsubsection{Cytokines.}

Chemokines and cytokines are other major types of protein biomarkers known for their significant role in regulating and stimulating intercellular immune cell signaling, which mediates $\beta$-cell destruction. Various cytokines during pre-diabetes get up-regulated, thereby investigating their role as surrogate serum markers [74-76]. It was postulated that chemokines and cytokines are highly elevated in patients positive to AAb. The main cytokines are IL-10 and IL-21. The serum CXCL1 can significantly differentiate T2D from T1D, which plays an important role in disease differentiation [77]. Cytokines are under investigation to explore their 
protective role in T1D management. It had been evaluated that cytokines are powerful manifestos of inflammation and elimination of microbes. But they lack therapeutic ventures. The therapeutic implications are limited due to the lack of organ specificity to the diabetes disease.

\subsubsection{Pro-insulin or C-peptide ratio.}

A study published by Diabetes care confirmed that the elevation in the serum ratio of pro-insulin to peptide-C (PI:C) indicates $\beta$-cell dysfunction, thereby reflecting misfolding in the insulin protein originating the endoplasmic reticulum. The elevated levels of C-peptides and pro-insulin in serum indicate the $\beta$-cell destruction and can be used to identify juvenile diabetes. In another study by Sims et al., they hypothesized that increased PI:C ratio, a biomarker of $\beta$-cell endoplasmic reticulum function, might be associated with T1D and concluded that this dysfunction might anticipate in T1D mainly in younger children [78]. This study concluded that stress-related biomarkers like intrinsic $\beta$-cell could become an important criterion for the early diagnosis of T1D. However, further studies would help to avert PI's use along with other biomarkers for detecting T1D in the pre-symptomatic phase.

\subsection{Prediction using nucleic-acid biomarkers.}

In some pre-clinical in-vivo studies and clinical reports, the involvement of stress pathways elemental to the $\beta$-cell for the development of T1D has been elucidated [79]. Also, in several studies, various assays have been developed that help quantify circulating unmethylated insulin DNA producing in the body due to apoptosis and necrosis, which may carry a variety of genetic alterations that can be related to disease development and progression. This is because certain cytosine-guanine sites are present in insulin genes that are often methylated in $\beta$-pancreatic cells; however, it is found as methylated in other tissues [80]. In T1D progression, this methylated insulin DNA is present in systemic circulation and thus become detectable. Thus, it can be concluded that measurement of this and methylated insulin DNA may reflect $\beta$-cell apoptosis or $\beta$-cell death [81].

Another milestone in the research of nucleic acid biomarker is laid by the development of transcriptomic fingerprint. This biomarker has been found in various blood-derived immunocyte cells, which include WBC, peripheral blood mononuclear cells, and even wholeblood. In recent research, it has been found out that certain miRNA present in the bloodstream can quantitatively reverse the action of transcription PCR. A genome-wide transcriptomics analysis in a study revealed that interferons (IFN) related to transcriptomics signatures were present in children with a high risk of T1D diabetes [82].

Another class of nucleic acid biomarker included MicroRNA, also called miRNAs, which are small non-coding RNAs responsible for regulating gene expression through mRNA. In a recent study, miRNA's role has been elucidated in regulating $\beta$-cell function and, therefore, prognosis associated with T1D [83]. Thus, it can be concluded that these nucleic-acid biomarkers withhold immense potential to be used to diagnose diabetes.

\subsection{Prediction using metabolic biomarkers.}

It has been well postulated that glucose is one of the elementary and pragmatic metabolic biomarkers used in the diagnosis of T1D. However, the use of glucose as a metabolic biomarker is not specific to T1D alone. Recent studies have concluded that certain amino acids 
along with some lipid metabolites are associated with T1D. Some scientists also believed that sphingolipids hold utmost importance in inflammation and insulin signaling pathway, which holds tremendous potential to be used as a biomarker [84]. Also, in a study executed by Torre et al., they concluded that phospholipids were found in scarce levels in the blood of patients with T1D during birth, prior to the diagnosis of T1D [85]. The previous study results concluded that extremely low levels of phospholipids are associated with accentuated risk of TID.

\section{Biomarkers Currently in Use for T1D}

The mechanism of action of some recently utilized biomarkers and their pharmacological activity has been summarized in Table $1[46,86,87]$.

Table 1. Mechanism of action and pharmacological activity of biomarkers.

\begin{tabular}{|c|c|c|}
\hline Biomarker & Mechanism of action & Effects and pharmacological activity \\
\hline Adiponectin & $\begin{array}{l}\text { Derived from adipose tissue in the } \\
\text { human body, it exhibits multiple anti- } \\
\text { inflammatory, insulin-sensitizing, and } \\
\text { anti-atherogenic effects. }\end{array}$ & $\begin{array}{l}\text { It acts via: } \\
\text { - Decreased level of adiponectin increases insulin resistance } \\
\text { - } \quad \text { It is inversely proportional to the risk of pre-diabetes. } \\
\text { - It is directly proportional to insulin sensitivity and } \\
\text { inversely to insulin secretion }\end{array}$ \\
\hline FetA & $\begin{array}{l}\text { It is a hepatic secretory glycol-protein } \\
\text { that promotes lipid-induced insulin } \\
\text { resistance }\end{array}$ & $\begin{array}{l}\text { - It is shown to exhibit activity in the development of Type } \\
2 \mathrm{DM} \text { and its associated complications }\end{array}$ \\
\hline$\alpha-\mathrm{HB}$ & $\begin{array}{l}\text { It is an organic byproduct of } \alpha- \\
\text { ketobutyrate }\end{array}$ & $\begin{array}{l}\text { Elevated } \alpha \text {-HB level in the body has seen to affect insulin } \\
\text { resistance, oxidative stress, and lipid oxidation }\end{array}$ \\
\hline $\begin{array}{l}\text { High-density } \\
\text { lipoprotein } \\
\text { (HDL) }\end{array}$ & One of the major lipoprotein & $\begin{array}{l}\text { Low HDL proportional to the progression from pre- } \\
\text { diabetes to diabetes } \\
\text { In patients with pre-diabetes } \beta \text {-cell dysfunction and } \\
\text { reduced insulin secretion is seen }\end{array}$ \\
\hline L-GPC & $\begin{array}{l}\text { Metabolite synthesized by } \\
\text { phospholipase A2 in the liver }\end{array}$ & $\begin{array}{ll}- & \text { This is a negative predictor of Type } 2 \text { diabetes mellitus } \\
\text { progression }\end{array}$ \\
\hline THBS1 & $\begin{array}{l}\text { Responsible for cellular modulation } \\
\text { phenotype, including stimulation of } \\
\text { vascular smooth muscles }\end{array}$ & $\begin{array}{l}\text { It is positively associated with: } \\
-\quad \text { Increased insulin resistance } \\
\text { - } \quad \text { Metabolic dysregulation in obesity } \\
\end{array}$ \\
\hline GPLD1 & $\begin{array}{l}\text { It is an insulin-mimicking signaling } \\
\text { pathway of } \\
\text { glycosylphosphatidylinositol } \\
\text { compounds }\end{array}$ & $\begin{array}{l}\text { It is positively associated with: } \\
-\quad \text { T2DM and pre-diabetes } \\
\text { - } \quad \text { HDL in serum (blood) }\end{array}$ \\
\hline
\end{tabular}

\section{Discussion and Future Prospective}

In today's modern world, the treatment of diabetes has become of utmost importance. It has been estimated that approximately 5 million people of the 18 million people with diabetes are not aware of suffering from this disease. According to the International Diabetes Federation survey, the number of cases with diabetes will substantially rise by 2035 . Also, in India, the situation is critical as recent epidemiological studies have concluded that nearly half of the total people with diabetes remain undetected, resulting in chronic complications. ICMR-India Diabetes has estimated that the level of undiagnosed cases with diabetes is more in the rural region than in urban. This leads to macro-vascular development (coronary artery disease, cerebrovascular diseases, and peripheral nerve disease) and micro-vascular disorders (neuropathy, nephropathy, and retinopathy).

Thus, early detection and timely treatment are important to reduce the risk of serious complications associated with diabetes. By doing this, we can prevent complications of cardiovascular disorder, blindness, renal failure, and amputation of limbs. It has been seen that 
patient with type 2 diabetes has no sign in symptoms in early stages. Also, in the case of T1D, this is generally detected earlier than T2DM due to its immediate symptoms that required immediate medical attention. Thus, early diagnosis of diabetes, especially pre-diabetes, is very important to curb and manage this disease at early stages, which has prevented chronic complications associated with diabetes.

In the past few decades, increasing efforts have been seen to develop novel T1D biomarkers. Unfortunately, due to the increased price and scarce information regarding the safety, efficacy, and therapeutic outcomes, biomarkers have not been put into use. To overcome these issues, scientists are exploring new strategies and novel methods to identify and characterize diabetes easily. Currently, diagnosis and diabetes progression rely mainly on glycemic indices. Novel biomarkers have the capability of identifying involving underlying pathology and etiology of dysglycemia. The discovery of these biomarkers can identify various lead pathways in the progression and management of diabetes. Also, the use of these biomarkers can effectively manage diabetes-related complications, which include diabetic neuropathy and diabetic nephropathy. In the Human Proteomics Organization (2004) meeting held in Beijing, Nobel Laureate Lee Hartwell mentioned that the evolution of biomarkers for the early detection and diagnosis of various diseases could revolutionize the pharmaceutical industry. This holds tremendous potential in identifying and thereby treating various lifethreatening conditions, including cancer, AIDS, diabetes, and various cardio-respiratory disorders.

\section{Conclusions}

With the increasing prevalence of T1D, greater avenues and opportunities for disease prevention and interventions are increasing at an alarming rate. With the advancement in the development of immunological measurements, T1D owing to its varied genotyping and presence of multiple antibodies, still provides a challenging environment for the development of specific biomarkers to predict T1D. However, considerable progress has been made in applying these biomarkers in the early detection of T1D. From the analysis made in this review, it can be concluded that novel biomarkers may overcome this hurdle and will help to combat this disorder by early detection and prognosis.

\section{Funding}

This review received no external funding.

\section{Acknowledgments}

The authors express gratitude to Chitkara College of Pharmacy, Chitkara University, Punjab, India, for motivational support for this review's compilation.

\section{Conflict of Interest}

The authors declare no conflict of interest.

\section{References}

1. WHO Diabetes. Available online: http://www.who.int/news-room/fact-sheets/detail/diabetes (accessed on 2 January 2020). 
2. Katsarou, A.; Gudbjörnsdottir, S.; Rawshani, A.; Dabelea, D.; Bonifacio, E.; Anderson, B.J.; Jacobsen, L.M.; Schatz, D.A.; Lernmark, Å. Type 1 diabetes mellitus. Nature Reviews Disease Primers 2017, 3, 17016, https://doi.org/10.1038/nrdp.2017.16.

3. Muchtar, E.; Blauwet Lori, A.; Gertz Morie, A. Restrictive Cardiomyopathy. Circul. Res. 2017, 121, 819837, https://doi.org/10.1161/CIRCRESAHA.117.310982.

4. Craig, M.E.; Kim, K.W.; Isaacs, S.R.; Penno, M.A.; Hamilton-Williams, E.E.; Couper, J.J.; Rawlinson, W.D. Early-life factors contributing to type 1 diabetes. Diabetologia 2019, 62, 1823-1834, https://doi.org/10.1007/s00125-019-4942-x.

5. Gupta, A.; Behl, T.; Sachdeva, M. Key milestones in the diabetes research: A comprehensive update. Obesity Medicine 2020, 17, 100183, https://doi.org/10.1016/j.obmed.2020.100183.

6. Gupta, A.; Behl, T.; Panichayupakaranan, P. A review of phytochemistry and pharmacology profile of Juglans regia. Obesity Medicine 2019, 16, 100142, https://doi.org/10.1016/j.obmed.2019.100142.

7. Ajjan, R.A.; Schroeder, V. Role of complement in diabetes. Mol. Immunol. 2019, 114, 270-277, https://doi.org/10.1016/j.molimm.2019.07.031.

8. Persson, F.; Rossing, P. Diagnosis of diabetic kidney disease: state of the art and future perspective. Kidney International Supplements 2018, 8, 2-7, https://doi.org/10.1016/j.kisu.2017.10.003.

9. Marcovecchio, M.L. Importance of Identifying Novel Biomarkers of Microvascular Damage in Type 1 Diabetes. Mol. Diagn. Ther. 2020, 24, 507-515, https://doi.org/10.1007/s40291-020-00483-6.

10. Rosenthal, J.; Tyor, W. Aging, comorbidities, and the importance of finding biomarkers for HIV-associated neurocognitive disorders. J. Neurovirol. 2019, 25, 673-685, https://doi.org/10.1007/s13365-019-00735-0.

11. Maestú, F.; Cuesta, P.; Hasan, O.; Fernandéz, A.; Funke, M.; Schulz, P.E. The Importance of the Validation of M/EEG With Current Biomarkers in Alzheimer's Disease. Front. Hum. Neurosci. 2019, 13, 17, https://doi.org/10.3389/fnhum.2019.00017.

12. Warshauer, J.T.; Bluestone, J.A.; Anderson, M.S. New frontiers in the treatment of type 1 diabetes. Cell Metab. 2020, 31, 46-61, https://doi.org/10.1016/j.cmet.2019.11.017.

13. Tooley, J.E.; Herold, K.C. Biomarkers in type 1 diabetes: application to the clinical trial setting. Current Opinion in Endocrinology, Diabetes and Obesity 21, https://doi.org/10.1097/MED.0000000000000076.

14. Chiarelli, F.; Giannini, C.; Primavera, M. Prediction and prevention of type 1 diabetes in children. Clinical Pediatric Endocrinology 2019, 28, 43-57, https://doi.org/10.1297/cpe.28.43.

15. Hörber, S.; Achenbach, P.; Schleicher, E.; Peter, A. Harmonization of immunoassays for biomarkers in diabetes mellitus. Biotechnol. Adv. 2020, 39, 107359, https://doi.org/10.1016/j.biotechadv.2019.02.015.

16. Qin, Y.; Zhang, S.; Shen, X.; Zhang, S.; Wang, J.; Zuo, M.; Cui, X.; Gao, Z.; Yang, J.; Zhu, H.; Chang, B. Evaluation of urinary biomarkers for prediction of diabetic kidney disease: a propensity score matching analysis. Ther. Adv. Endocrinol. Metab. 2019, 10, 2042018819891110, https://doi.org/10.1177/2042018819891110.

17. Uwaezuoke, S.N. The role of novel biomarkers in predicting diabetic nephropathy: a review. Int. J. Nephrol. Renovasc. Dis. 2017, 10, 221, https://doi.org/10.2147/IJNRD.S143186.

18. Wenzlau, J.M.; Hutton, J.C. Novel diabetes autoantibodies and prediction of type 1 diabetes. Curr. Diab. Rep. 2013, 13, 608-615, https://doi.org/10.1007/s11892-013-0405-9.

19. Lee, J.-H.; Kim, B.-H.; Yoon, Y.-C.; Kim, J.-G.; Park, Y.-E.; Park, H.-S.; Kwun, I.-S.; Kwon, G.-S.; Lee, J.B. Effects against obesity and diabetes of red pepper (Capsicum annuum L.) fermented with lactic acid bacteria. Journal of Life Science 2019, 29, 354-361, https://doi.org/10.5352/JLS.2019.29.3.354.

20. Huynh, T. Clinical and Laboratory Aspects of Insulin Autoantibody-Mediated Glycaemic Dysregulation and Hyperinsulinaemic Hypoglycaemia: Insulin Autoimmune Syndrome and Exogenous Insulin Antibody Syndrome. The Clinical Biochemist Reviews 2020, 41, 93, https://doi.org/10.33176/AACB-20-00008.

21. Bonifacio, E.; Achenbach, P. Birth and coming of age of islet autoantibodies. Clin. Exp. Immunol. 2019, 198, 294-305, https://doi.org/10.1111/cei.13360.

22. Baumann, K.; Kesselring, K.; Lampasona, V.; Walschus, U.; Kerner, W.; Wassmuth, R.; Schlosser, M. Autoantibodies against zinc transporter 8 further stratify the autoantibody-defined risk for type 1 diabetes in a general population of schoolchildren and have distinctive isoform binding patterns in different forms of autoimmune diabetes: results from the Karlsburg Type 1 Diabetes Risk Study. Diabet. Med. 2020, n/a, e14389, https://doi.org/10.1111/dme.14389.

23. Shields, B.M.; Shepherd, M.; Hudson, M.; McDonald, T.J.; Colclough, K.; Peters, J.; Knight, B.; Hyde, C.; Ellard, S.; Pearson, E.R.; Hattersley, A.T. Population-Based Assessment of a Biomarker-Based Screening 
Pathway to Aid Diagnosis of Monogenic Diabetes in Young-Onset Patients. Diabetes Care 2017, 40, 1017, https://doi.org/10.2337/dc17-0224.

24. Zhong, T.; Tang, R.; Gong, S.; Li, J.; Li, X.; Zhou, Z. The remission phase in type 1 diabetes: Changing epidemiology, definitions, and emerging immuno-metabolic mechanisms. Diabetes Metab. Res. Rev. 2020, 36, e3207, https://doi.org/10.1002/dmrr.3207.

25. Terasaki, M.; Yashima, H.; Mori, Y.; Saito, T.; Matsui, T.; Hiromura, M.; Kushima, H.; Osaka, N.; Ohara, M.; Fukui, T.; Hirano, T.; Yamagishi, S.-i. A Dipeptidyl Peptidase-4 Inhibitor Inhibits Foam Cell Formation of Macrophages in Type 1 Diabetes via Suppression of CD36 and ACAT-1 Expression. Int. J. Mol. Sci. 2020, 21, https://doi.org/10.3390/ijms21134811.

26. Yu, H.W.; Lee, Y.J.; Im Cho, W.; Lee, Y.A.; Shin, C.H.; Yang, S.W. Preserved C-peptide levels in overweight or obese compared with underweight children upon diagnosis of type 1 diabetes mellitus. Annals of Pediatric Endocrinology \& Metabolism 2015, 20, 92, https://doi.org/10.6065/apem.2015.20.2.92.

27. Yu, M.G.; Keenan, H.A.; Shah, H.S.; Frodsham, S.G.; Pober, D.; He, Z.; Wolfson, E.A.; D’Eon, S.; Tinsley, L.J.; Bonner-Weir, S.; Pezzolesi, M.G.; King, G.L. Residual $\beta$ cell function and monogenic variants in longduration type 1 diabetes patients. The Journal of Clinical Investigation 2019, 129, 3252-3263, https://doi.org/10.1172/JCI127397.

28. Leighton, E.; Sainsbury, C.A.R.; Jones, G.C. A Practical Review of C-Peptide Testing in Diabetes. Diabetes Ther. 2017, 8, 475-487, https://doi.org/10.1007/s13300-017-0265-4.

29. Zhi, W.; Purohit, S.; Carey, C.; Wang, M.; She, J.-X. Proteomic Technologies for the Discovery of Type 1 Diabetes Biomarkers. J. Diabetes Sci. Technol. 2010, 4, 993-1002, https://doi.org/10.1177/193229681000400431.

30. Saisho, Y.; Butler, A.E.; Manesso, E.; Elashoff, D.; Rizza, R.A.; Butler, P.C. $\beta$-Cell Mass and Turnover in Humans. Diabetes Care 2013, 36, 111, https://doi.org/10.2337/dc12-0421.

31. Atkinson, M.A.; von Herrath, M.; Powers, A.C.; Clare-Salzler, M. Current Concepts on the Pathogenesis of Type 1 Diabetes-Considerations for Attempts to Prevent and Reverse the Disease. Diabetes Care 2015, 38, 979, https://doi.org/10.2337/dc15-0144.

32. Kotwal, A.; Haddox, C.; Block, M.; Kudva, Y.C. Immune checkpoint inhibitors: an emerging cause of insulin-dependent diabetes. BMJ Open Diabetes Research and Care 2019, 7, http://dx.doi.org/10.1136/bmjdrc-2018-000591.

33. Borchers, A.T.; Uibo, R.; Gershwin, M.E. The geoepidemiology of type 1 diabetes. Autoimmun. Rev. 2010, 9, A355-A365, https://doi.org/10.1016/j.autrev.2009.12.003.

34. Bruno, G.; Novelli, G.; Panero, F.; Perotto, M.; Monasterolo, F.; Bona, G.; Perino, A.; Rabbone, I.; CavalloPerin, P.; Cerutti, F.; Piedmont Study Group for Diabetes, E. The incidence of type 1 diabetes is increasing in both children and young adults in Northern Italy: 1984-2004 temporal trends. Diabetologia 2009, 52, 2531-2535, https://doi.org/10.1007/s00125-009-1538-x.

35. Bhagat, N.; Zarbin, M.A. Epidemiology, Risk Factors, and Pathophysiology of Diabetic Retinopathy. In Clinical Strategies in the Management of Diabetic Retinopathy: A Step-by-Step Guide for Ophthalmologists, Bandello, F., Zarbin, M.A., Lattanzio, R., Zucchiatti, I., Eds. Springer International Publishing: Cham, 2019, 1-19. Springer, Cham, https://doi.org/10.1007/978-3-319-96157-6_1.

36. Levitt, N.S. Diabetes in Africa: epidemiology, management and healthcare challenges. Heart 2008, 94, 13761382, http://dx.doi.org/10.1136/hrt.2008.147306.

37. Wang, Y.; Wang, Z.; Zhang, H. Identification of diagnostic biomarker in patients with gestational diabetes mellitus based on transcriptome-wide gene expression and pattern recognition. J. Cell. Biochem. 2019, 120, 1503-1510, https://doi.org/10.1002/jcb.27279.

38. Berchuck, A.; Iversen, E.S.; Lancaster, J.M.; Pittman, J.; Luo, J.; Lee, P.; Murphy, S.; Dressman, H.K.; Febbo, P.G.; West, M.; Nevins, J.R.; Marks, J.R. Patterns of Gene Expression That Characterize Long-term Survival in Advanced Stage Serous Ovarian Cancers. Clin. Cancer. Res. 2005, 11, 3686, https://doi.org/10.1158/10780432.CCR-04-2398.

39. Huang, E.; Cheng, S.H.; Dressman, H.; Pittman, J.; Tsou, M.H.; Horng, C.F.; Bild, A.; Iversen, E.S.; Liao, M.; Chen, C.M. Gene expression predictors of breast cancer outcomes. The Lancet 2003, 361, 1590-1596, https://doi.org/10.1016/S0140-6736(03)13308-9.

40. Yu, K.; Huang, Z.; Zhou, J.; Lang, J.; Wang, Y.; Yin, X.; Zhou, Y.; Zhao, D. Transcriptome profiling of microRNAs associated with latent autoimmune diabetes in adults (LADA). Sci. Rep. 2019, 9, 11347, https://doi.org/10.1038/s41598-019-47726-z. 
41. Tirado, C.A.; Chen, W.; García, R.; Kohlman, K.A.; Rao, N. Genomic profiling using array comparative genomic hybridization define distinct subtypes of diffuse large b-cell lymphoma: a review of the literature. J. Hematol. Oncol. 2012, 5, 54, https://doi.org/10.1186/1756-8722-5-54.

42. Kaizer, E.C.; Glaser, C.L.; Chaussabel, D.; Banchereau, J.; Pascual, V.; White, P.C. Gene Expression in Peripheral Blood Mononuclear Cells from Children with Diabetes. The Journal of Clinical Endocrinology \& Metabolism 2007, 92, 3705-3711, https://doi.org/10.1210/jc.2007-0979.

43. Planas, R.; Carrillo, J.; Sanchez, A.; Ruiz de Villa, M.C.; Nuñez, F.; Verdaguer, J.; James, R.F.L.; PujolBorrell, R.; Vives-Pi, M. Gene expression profiles for the human pancreas and purified islets in Type 1 diabetes: new findings at clinical onset and in long-standing diabetes. Clin. Exp. Immunol. 2010, 159, 23-44, https://doi.org/10.1111/j.1365-2249.2009.04053.x.

44. Elo, L.L.; Mykkänen, J.; Nikula, T.; Järvenpää, H.; Simell, S.; Aittokallio, T.; Hyöty, H.; Ilonen, J.; Veijola, R.; Simell, T.; Knip, M.; Simell, O.; Lahesmaa, R. Early suppression of immune response pathways characterizes children with pre-diabetes in genome-wide gene expression profiling. J. Autoimmun. 2010, 35, 70-76, https://doi.org/10.1016/j.jaut.2010.03.001.

45. Han, D.; Cai, X.; Wen, J.; Matheson, D.; Skyler, J.S.; Kenyon, N.S.; Chen, Z. Innate and adaptive immune gene expression profiles as biomarkers in human type 1 diabetes. Clin. Exp. Immunol. 2012, 170, 131-138, https://doi.org/10.1111/j.1365-2249.2012.04650.x.

46. Mathieu, C.; Lahesmaa, R.; Bonifacio, E.; Achenbach, P.; Tree, T. Immunological biomarkers for the development and progression of type 1 diabetes. Diabetologia 2018, 61, 2252-2258, https://doi.org/10.1007/s00125-018-4726-8.

47. Planas, R.; Pujol-Borrell, R.; Vives-Pi, M. Global gene expression changes in type 1 diabetes: Insights into autoimmune response in the target organ and in the periphery. Immunol. Lett. 2010, 133, 55-61, https://doi.org/10.1016/j.imlet.2010.08.001.

48. Guan, L.; Luo, Q.; Liang, N.; Liu, H. A prognostic prediction system for hepatocellular carcinoma based on gene co-expression network. Exp. Ther. Med. 2019, 17(6), 4506-4516. https://doi.org/10.3892/etm.2019.7494.

49. Reynier, F.; Pachot, A.; Paye, M.; Xu, Q.; Turrel-Davin, F.; Petit, F.; Hot, A.; Auffray, C.; Bendelac, N.; Nicolino, M.; Mougin, B.; Thivolet, C. Specific gene expression signature associated with development of autoimmune type-I diabetes using whole-blood microarray analysis. Genes Immun. 2010, 11, 269-278, https://doi.org/10.1038/gene.2009.112.

50. Heinzel, A.; Kammer, M.; Mayer, G.; Reindl-Schwaighofer, R.; Hu, K.; Perco, P.; Eder, S.; Rosivall, L.; Mark, P.B.; Ju, W.; Kretzler, M.; Gilmour, P.; Wilson, J.M.; Duffin, K.L.; Abdalla, M.; McCarthy, M.I.; Heinze, G.; Heerspink, H.L.; Wiecek, A.; Gomez, M.F.; Oberbauer, R. Validation of Plasma Biomarker Candidates for the Prediction of eGFR Decline in Patients With Type 2 Diabetes. Diabetes Care 2018, 41, 1947, https://doi.org/10.2337/dc18-0532.

51. Emamian, E.S.; Leon, J.M.; Lessard, C.J.; Grandits, M.; Baechler, E.C.; Gaffney, P.M.; Segal, B.; Rhodus, N.L.; Moser, K.L. Peripheral blood gene expression profiling in Sjögren's syndrome. Genes Immun. 2009, 10, 285-296, https://doi.org/10.1038/gene.2009.20.

52. Stechova, K.; Kolar, M.; Blatny, R.; Halbhuber, Z.; Vcelakova, J.; Hubackova, M.; Petruzelkova, L.; Sumnik, Z.; Obermannova, B.; Pithova, P.; Stavikova, V.; Krivjanska, M.; Neuwirth, A.; Kolouskova, S.; Filipp, D. Healthy First-Degree Relatives of Patients with Type 1 Diabetes Exhibit Significant Differences in Basal Gene Expression Pattern of Immunocompetent Cells Compared to Controls: Expression Pattern as Predeterminant of Autoimmune Diabetes. Scand. J. Immunol. 2012, 75, 210-219, https://doi.org/10.1111/j.1365-3083.2011.02637.x.

53. Wang, X.; Jia, S.; Geoffrey, R.; Alemzadeh, R.; Ghosh, S.; Hessner, M.J. Identification of a Molecular Signature in Human Type 1 Diabetes Mellitus Using Serum and Functional Genomics. The Journal of Immunology 2008, 180, 1929, https://doi.org/10.4049/jimmunol.180.3.1929.

54. Meng, Q.; Ge, S.; Yan, W.; Li, R.; Dou, J.; Wang, H.; Wang, B.; Ma, Q.; Zhou, Y.; Song, M.; Yu, X.; Wang, H.; Yang, X.; Liu, F.; Alzain, M.A.; Yan, Y.; Zhang, L.; Wu, L.; Zhao, F.; He, Y.; Guo, X.; Chen, F.; Xu, W.; Garcia, M.; Menon, D.; Wang, Y.; Mu, Y.; Wang, W. Screening for potential serum-based proteomic biomarkers for human type 2 diabetes mellitus using MALDI-TOF MS. PROTEOMICS - Clinical Applications 2017, 11, 1600079, https://doi.org/10.1002/prca.201600079.

55. Wenzlau, J.M.; Moua, O.; Sarkar, S.A.; Yu, L.; Rewers, M.; Eisenbarth, G.S.; Davidson, H.W.; Hutton, J.C. S1C30A8 Is a Major Target of Humoral Autoimmunity in Type 1 Diabetes and a Predictive Marker in Prediabetes. Ann. N. Y. Acad. Sci. 2008, 1150, 256-259, https://doi.org/10.1196/annals.1447.029. 
56. Zürbig, P.; Siwy, J.; Mischak, H. Emerging urine-based proteomic biomarkers as valuable tools in the management of chronic kidney disease. Expert Rev. Mol. Diagn. 2019, 19, 853-856, https://doi.org/10.1080/14737159.2019.1657406.

57. Youngblood, H.; Robinson, R.; Sharma, A.; Sharma, S. Proteomic Biomarkers of Retinal Inflammation in Diabetic Retinopathy. Int. J. Mol. Sci. 2019, 20, https://doi.org/10.3390/ijms20194755.

58. Vecchio, F.; Messina, G.; Giovenzana, A.; Petrelli, A. New Evidence of Exocrine Pancreatopathy in Presymptomatic and Symptomatic Type 1 Diabetes. Curr. Diab. Rep. 2019, 19, 92, https://doi.org/10.1007/s11892-019-1223-5.

59. Chen, L.; Su, W.; Chen, H.; Chen, D.-Q.; Wang, M.; Guo, Y.; Zhao, Y.-Y. Chapter Four - Proteomics for Biomarker Identification and Clinical Application in Kidney Disease. In Adv. Clin. Chem., Makowski, G.S., Ed. Elsevier: 2018; Vol. 85, 91-113, https://doi.org/10.1016/bs.acc.2018.02.005.

60. Moulder, R.; Bhosale, S.D.; Lahesmaa, R.; Goodlett, D.R. The progress and potential of proteomic biomarkers for type 1 diabetes in children. Expert Review of Proteomics 2017, 14, 31-41, https://doi.org/10.1080/14789450.2017.1265449.

61. Ferreira, J.P.; Sharma, A.; Mehta, C.; Bakris, G.; Rossignol, P.; White, W.B.; Zannad, F. Multi-proteomic approach to predict specific cardiovascular events in patients with diabetes and myocardial infarction: findings from the EXAMINE trial. Clin. Res. Cardiol. 2020, 1-4, https://doi.org/10.1007/s00392-020-017293 .

62. Sarkar, S.; Berry, M.D. Involvement of Organic Cation Transporter 2 and a Na+-dependent active transporter in p-tyramine transport across Caco-2 intestinal cells. Life Sci. 2020, 253, 117696, https://doi.org/10.1016/j.lfs.2020.117696.

63. Park, S.G.; Park, H.S.; Jeong, I.-K.; Cho, Y.M.; Lee, H.K.; Kang, Y.-S.; Kim, S.; Park, K.S. Autoantibodies against aminoacyl-tRNA synthetase: novel diagnostic marker for type 1 diabetes mellitus. Biomarkers 2010, 15, 358-366, https://doi.org/10.3109/13547501003777823.

64. Zhou, T.; Huang, L.; Wang, M.; Chen, D.; Chen, Z.; Jiang, S.-W. A Critical Review of Proteomic Studies in Gestational Diabetes Mellitus. Journal of Diabetes Research 2020, 2020, 6450352, https://doi.org/10.1155/2020/6450352.

65. Cabrera-Rode, E.; Diaz-Horta, O.; Fernandez, L.E.; Carr, A.; Marquina, G.; Valiente, O.; Gonzalez-Suarez, R.M.; Uriarte, A. Glycolipids as the Major Autoantigens of Cytoplasmatic Islet Cell Antibodies. Autoimmunity 1995, 20, 145-151, https://doi.org/10.3109/08916939508993345.

66. Roep, B.O.; Thomaidou, S.; van Tienhoven, R.; Zaldumbide, A. Type 1 diabetes mellitus as a disease of the $\beta$-cell (do not blame the immune system?). Nature Reviews Endocrinology 2020, https://doi.org/10.1038/s41574-020-00443-4.

67. Quandt, Z.; Young, A.; Anderson, M. Immune checkpoint inhibitor diabetes mellitus: a novel form of autoimmune diabetes. Clin. Exp. Immunol. 2020, 200, 131-140, https://doi.org/10.1111/cei.13424.

68. Berger, C.; Zdzieblo, D. Glucose transporters in pancreatic islets. Pflügers Archiv - European Journal of Physiology 2020, 472, 1249-1272, https://doi.org/10.1007/s00424-020-02383-4.

69. Lindhardt, M.; Persson, F.; Zürbig, P.; Stalmach, A.; Mischak, H.; de Zeeuw, D.; Lambers Heerspink, H.; Klein, R.; Orchard, T.; Porta, M.; Fuller, J.; Bilous, R.; Chaturvedi, N.; Parving, H.-H.; Rossing, P. Urinary proteomics predict onset of microalbuminuria in normoalbuminuric type 2 diabetic patients, a sub-study of the DIRECT-Protect 2 study. Nephrology Dialysis Transplantation 2017, 32, 1866-1873, https://doi.org/10.1093/ndt/gfw292.

70. Razek, A.A.K.A.; Al-Adlany, M.A.A.A.; Alhadidy, A.M.; Atwa, M.A.; Abdou, N.E.A. Diffusion tensor imaging of the renal cortex in diabetic patients: correlation with urinary and serum biomarkers. Abdominal Radiology 2017, 42, 1493-1500, https://doi.org/10.1007/s00261-016-1021-3.

71. Vilar-Gomez, E.; Calzadilla-Bertot, L.; Friedman, S.L.; Gra-Oramas, B.; Gonzalez-Fabian, L.; Lazo-del Vallin, S.; Diago, M.; Adams, L.A. Serum biomarkers can predict a change in liver fibrosis 1 year after lifestyle intervention for biopsy-proven NASH. Liver International 2017, 37, 1887-1896, https://doi.org/10.1111/liv.13480.

72. Motawi, T.K.; Shehata, N.I.; ElNokeety, M.M.; El-Emady, Y.F. Potential serum biomarkers for early detection of diabetic nephropathy. Diabetes Res. Clin. Pract. 2018, 136, 150-158, https://doi.org/10.1016/j.diabres.2017.12.007.

73. Zhao, D.; Shen, L.; Wei, Y.; Xie, J.; Chen, S.; Liang, Y.; Chen, Y.; Wu, H. Identification of candidate biomarkers for the prediction of gestational diabetes mellitus in the early stages of pregnancy using iTRAQ 
quantitative proteomics. PROTEOMICS $\quad-$ Clinical Applications 2017, 11, 1600152, https://doi.org/10.1002/prca.201600152.

74. Bevc, S.; Hojs, N.; Knehtl, M.; Ekart, R.; Hojs, R. Cystatin C as a predictor of mortality in elderly patients with chronic kidney disease. The Aging Male 2019, 22, 62-67, https://doi.org/10.1080/13685538.2018.1479386.

75. Verma, S.; Hussain, M.E. Obesity and diabetes: An update. Diabetes \& Metabolic Syndrome: Clinical Research \& Reviews 2017, 11, 73-79, https://doi.org/10.1016/j.dsx.2016.06.017.

76. Akash, M.S.H.; Rehman, K.; Liaqat, A. Tumor Necrosis Factor-Alpha: Role in Development of Insulin Resistance and Pathogenesis of Type 2 Diabetes Mellitus. J. Cell. Biochem. 2018, 119, 105-110, https://doi.org/10.1002/jcb.26174.

77. Chen, C.; Wang, C.; Hu, C.; Han, Y.; Zhao, L.; Zhu, X.; Xiao, L.; Sun, L. Normoalbuminuric diabetic kidney disease. Front. Med. 2017, 11, 310-318, https://doi.org/10.1007/s11684-017-0542-7.

78. Sims, E.K.; Chaudhry, Z.; Watkins, R.; Syed, F.; Blum, J.; Ouyang, F.; Perkins, S.M.; Mirmira, R.G.; Sosenko, J.; DiMeglio, L.A.; Evans-Molina, C. Elevations in the Fasting Serum Proinsulin-to-C-Peptide Ratio Precede the Onset of Type 1 Diabetes. Diabetes Care 2016, 39, 1519, https://doi.org/10.2337/dc152849.

79. Sims, E.K.; Mirmira, R.G.; Evans-Molina, C. The role of beta-cell dysfunction in early type 1 diabetes. Current Opinion in Endocrinology, Diabetes and Obesity 2020, 27, https://doi.org/10.1097/MED.0000000000000548.

80. Bigagli, E.; Lodovici, M. Circulating Oxidative Stress Biomarkers in Clinical Studies on Type 2 Diabetes and Its Complications. Oxid. Med. Cell. Longev. 2019, 2019, 5953685, https://doi.org/10.1155/2019/5953685.

81. Yi, L.; Swensen, A.C.; Qian, W.-J. Serum biomarkers for diagnosis and prediction of type 1 diabetes. Translational Research 2018, 201, 13-25, https://doi.org/10.1016/j.trsl.2018.07.009.

82. Salek-Maghsoudi, A.; Vakhshiteh, F.; Torabi, R.; Hassani, S.; Ganjali, M.R.; Norouzi, P.; Hosseini, M.; Abdollahi, M. Recent advances in biosensor technology in assessment of early diabetes biomarkers. Biosensors Bioelectron. 2018, 99, 122-135, https://doi.org/10.1016/j.bios.2017.07.047.

83. Guo, C.; Ding, P.; Xie, C.; Ye, C.; Ye, M.; Pan, C.; Cao, X.; Zhang, S.; Zheng, S. Potential application of the oxidative nucleic acid damage biomarkers in detection of diseases. Oncotarget 2017, 8, 75767, https://doi.org/10.18632/oncotarget.20801.

84. Barrios, C.; Zierer, J.; Würtz, P.; Haller, T.; Metspalu, A.; Gieger, C.; Thorand, B.; Meisinger, C.; Waldenberger, M.; Raitakari, O.; Lehtimäki, T.; Otero, S.; Rodríguez, E.; Pedro-Botet, J.; Kähönen, M.; AlaKorpela, M.; Kastenmüller, G.; Spector, T.D.; Pascual, J.; Menni, C. Circulating metabolic biomarkers of renal function in diabetic and non-diabetic populations. Sci. Rep. 2018, 8, 15249, https://doi.org/10.1038/s41598-018-33507-7.

85. Rodrigo, N.; Glastras, S.J. The Emerging Role of Biomarkers in the Diagnosis of Gestational Diabetes Mellitus. Journal of Clinical Medicine 2018, 7, https://doi.org/10.3390/jcm7060120

86. Bonifacio, E. Predicting Type 1 Diabetes Using Biomarkers. Diabetes Care 2015, 38, 989, https://doi.org/10.2337/dc15-0101.

87. Speake, C.; Odegard, J.M. Evaluation of Candidate Biomarkers of Type 1 Diabetes via the Core for Assay Validation. Biomark. Insights 2015, 10s4, BMI.S29697, https://doi.org/10.4137/BMI.S29697. 